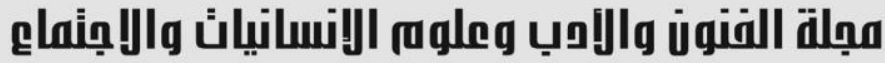

Journal of Arts, Literature, Humanities and Social Sciences www.jalhss.com

\section{المقاربة الدلالية في مدرسة جنيف البنيوية}

\author{
أ.م.د. حسام عدنان الياسري \\ كلية الآداب ـ جامعة القادسية ــ العراق \\ م.م. مصطظى هاتئ بريهي \\ كلية الآداب ـ جامعة القادسية ــ آلعراق
}

|لماخص

يعرض هذا البحث صورة واضحة لمدرسة جنيف اللسانية ويذكر روادها ويوضح أثرهم في تغيير مسار البنيوية، فمدرسة جنيف انطلقت من لسانيات سوسير و أضافت لها أبعادا أُخر، و هي الجوانب الدلالية، وكذلك جعل الكلام موضوع الدر اسة وغرضها فهي بذلك تنتمي للسانيات الكلام. وقد تناول البحث مقاربتين لعالمين من علماء اللسانيات و هما شارل بالي وسيثهاي ولكل منهما خصوصيته وآراؤه بحسب مرجعياته المعرفية، فقد بنى الأول نظريته على أسس عقلانية، وأسسَ للأسلوبية المرتبطة بالمفاهيم الذهنية الافتر اضية، أما سيشهابي فكانت مقاربته قائمة على أسس نفسية ، وقد حاولنا توضيح السمات النظرية و المنهجية لكل مقاربة، وبيان أوجه التشابه و الاختلاف، وركزنا على المو اضع التي تخص در اسة المعنى في هذه المدرسة اللسانية البنيوية. 


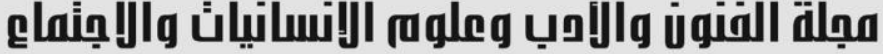

Journal of Arts, Literature, Humanities and Social Sciences www.jalhss.com

\section{The Semantic Approach at the Geneva Structuralism School}

Assist. Prof. Dr. Husam Adnan Al- Yasiri

College of Arts - University of Qadisiyah - Iraq

Mustafa Hatef Buraihi

College of Arts - University of Qadisiyah - Iraq

\begin{abstract}
The research presents a clear picture of the Geneva School and mention their pioneers and explains their impact on changing the structure of the structure, and the Geneva school was launched from Lasos Suzer and added other dimensions, and the semantic aspects, as well The research has addressed two of the worlds of linguistics, Charles Bali and Sishhai, and each of them, and his privacy, according to his cognitive references, the first of his theory was built on rational bases, and founded by the platform associated with concepts.
\end{abstract}

Keywords: Stylistic, Expressionist, Charles Bali, Seshhai, Structural Linguistics. 


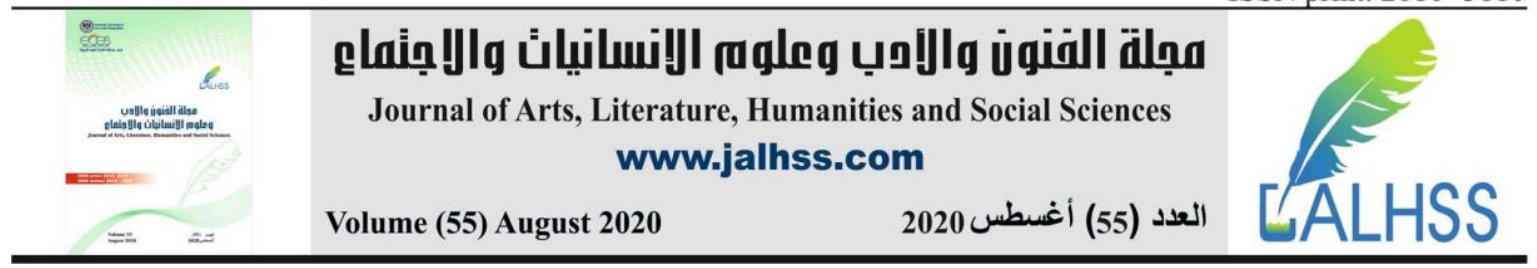

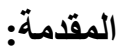

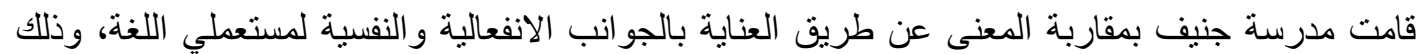

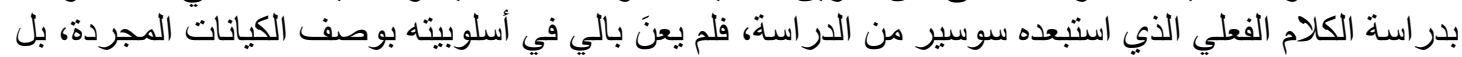

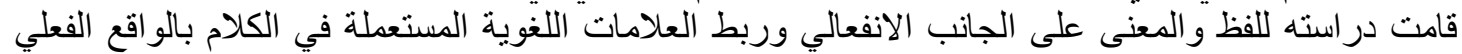

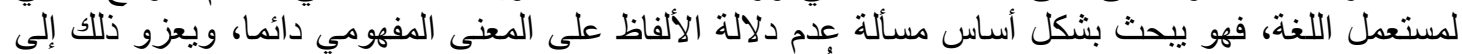
الجو انب الانفعالية و الوجدانية التي تضفي معاني أُخر بحسب دلان البعد الانفعالي لمستعملي اللغة.

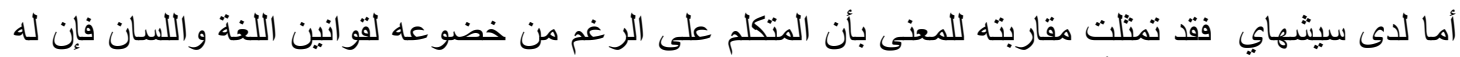

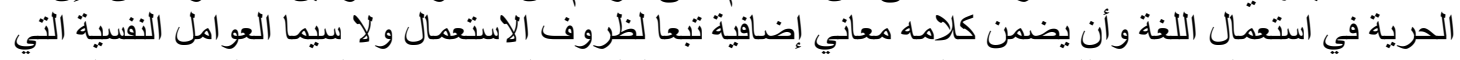

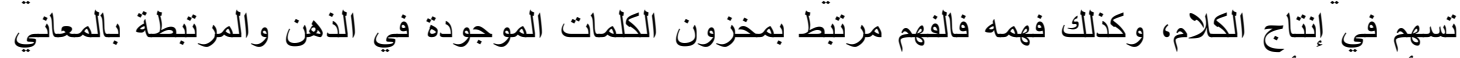
و الأفكار و والأبعاد النفسية.

\section{المقاربة الدلالية في مدرسة جنيف اللسانية :}

أعد مدرسة جنيف الأكثر قرباً من سوسير؛ لأن مؤسسيها من زملائه وتلاميذه في جنيف، وتدرج (ميلكا

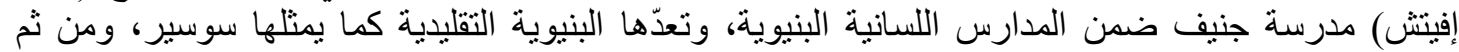

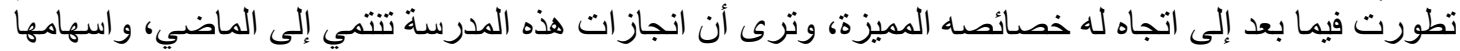

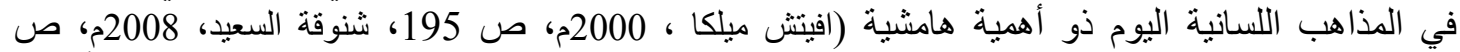

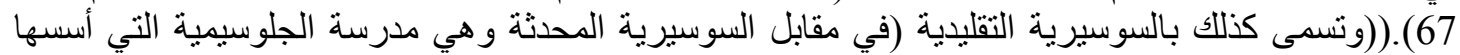

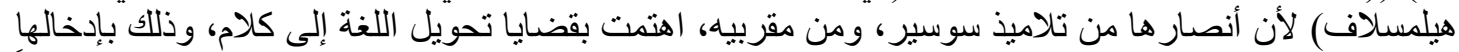

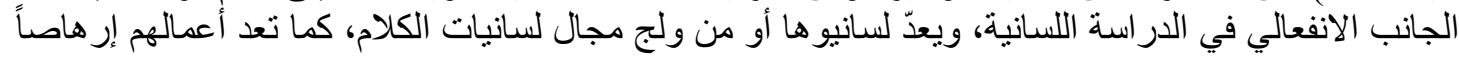

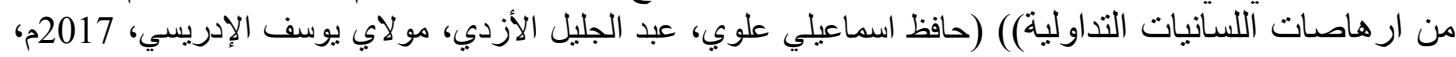
ص 283) فنظرياتهم قريبة من التداولية، و التداولية تهتم بالاستعمال المرتبط بقصدية مالية ألمتكلم و المعنى.

وتجدر الإشارة إلى أن مدرسة جنيف لم تكن تصدر عن فكرة رئيسة يتوخاها كل أعضائها، بل كان لكل عضو الإنو

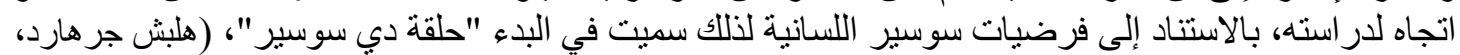

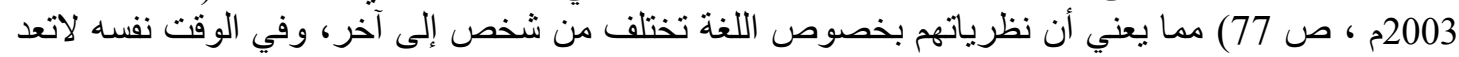
كل نتاجاتهم الكتابية معبرة عن مدرسة جنيف.

لذلك سنبدأ بالأفكار العامة لمدرسة جنيف، ونرى مدى معالجتهم للمعنى، ولن يكون اهتمامنا بالجو انب اللسانية إلا الإنيا

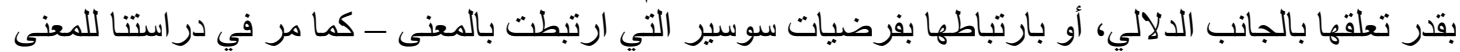
في لسانيات سوسير - وبالدالالة والعلامة اللغوية.

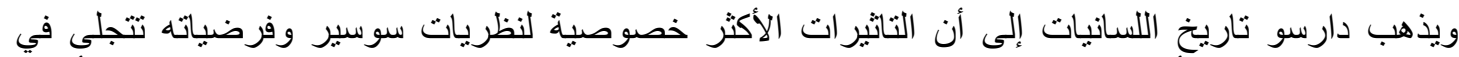

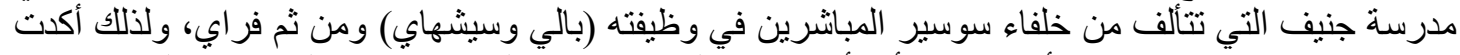

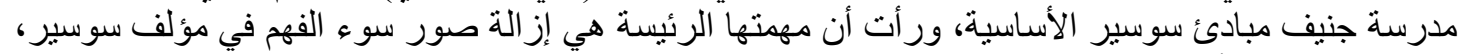

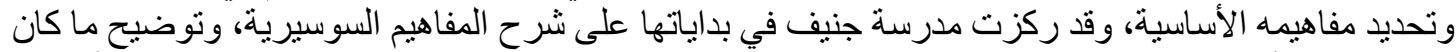

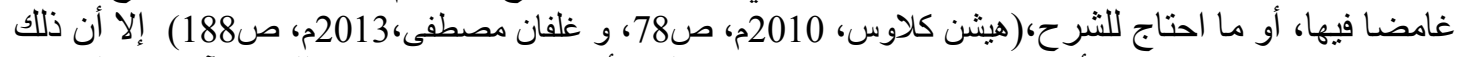

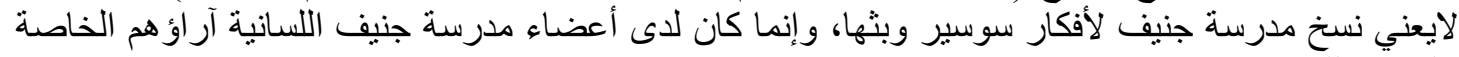
بالدرس اللساني.

وييدو أن لسانيات مدرسة جنيف تركز در استها على جانبين مهمين يرتبطان بالمعنى هما : الجانب الأول : يتمثل

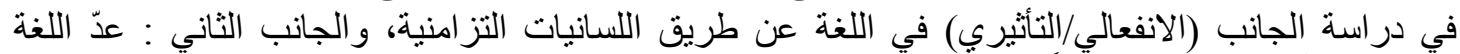

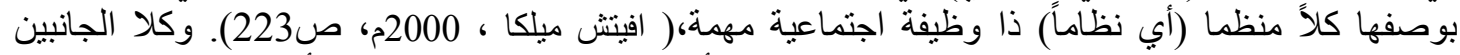

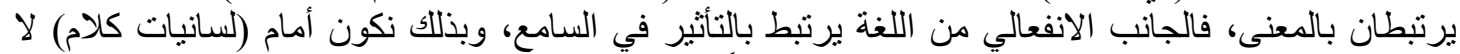

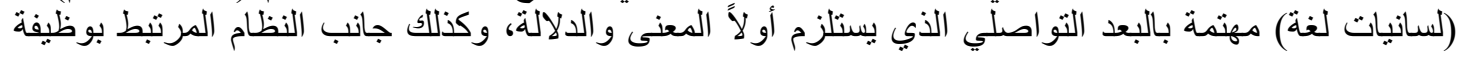




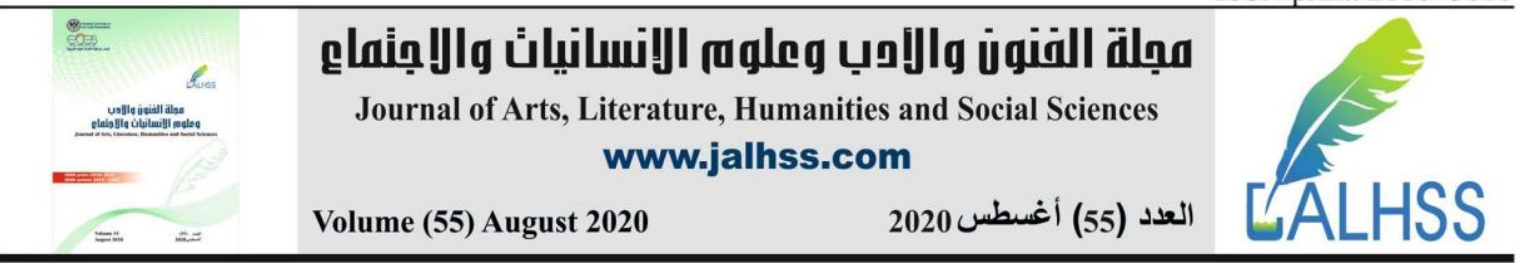

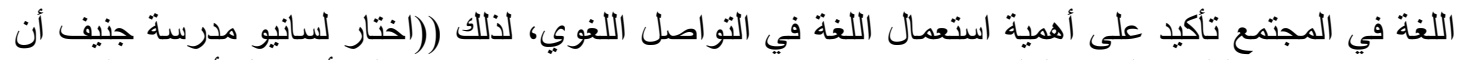

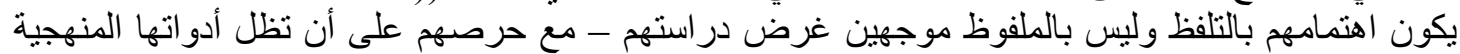

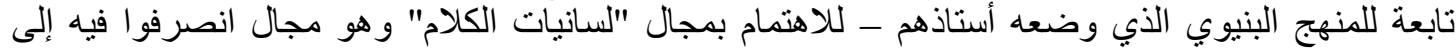

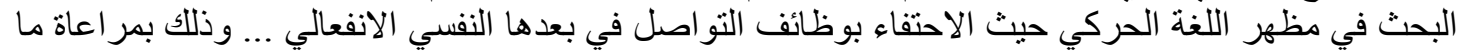

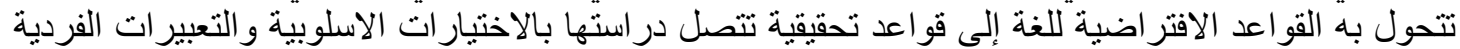

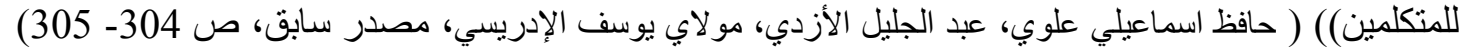

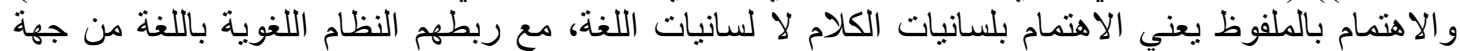

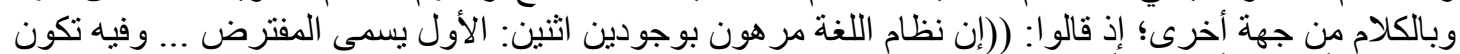

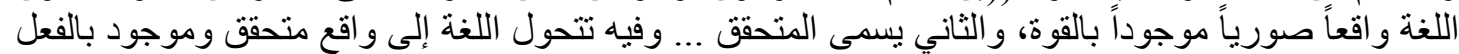

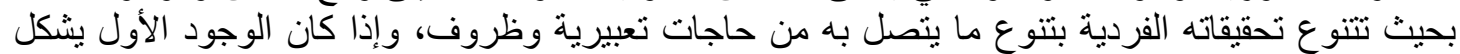

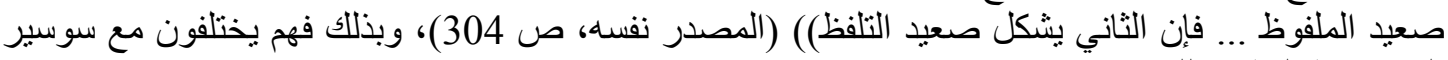
الذي يربط النظام باللغة.

وبعد أن لاحظنا المبادئ العامة المرتبطة بالمعنى في مدرسة جنيف، سننتقل إلى النظريات اللسانية المرتبطة

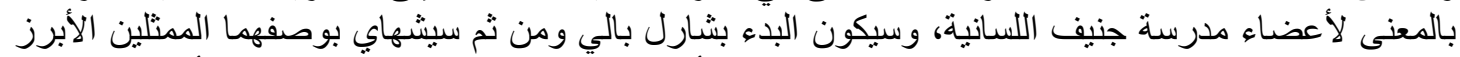

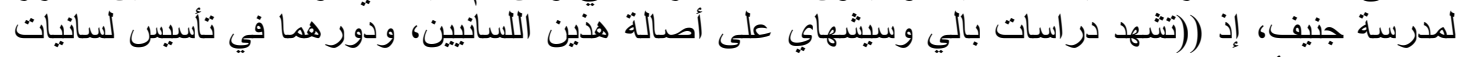

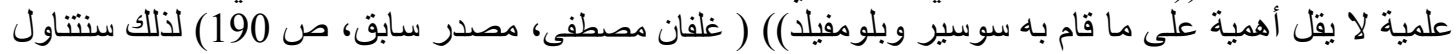
لسانيات بالي وسيشهاي ودر اسة المعنى فيهما على النحو الآتي:

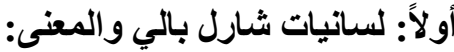

ارتبطت باسم مدرسة جنيف فكرة فحص الجانب (الانفعالي) في اللغة بلحاظ الأسلوب، وترتبط هذه الفرضية

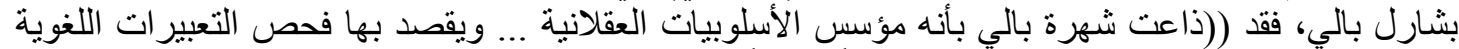

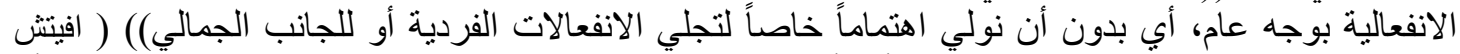

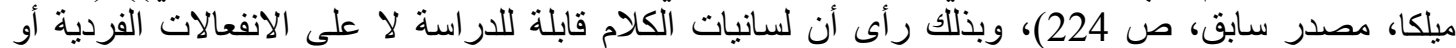

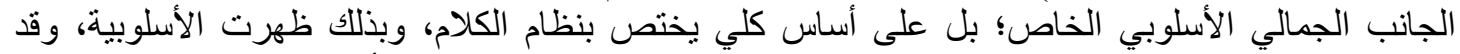

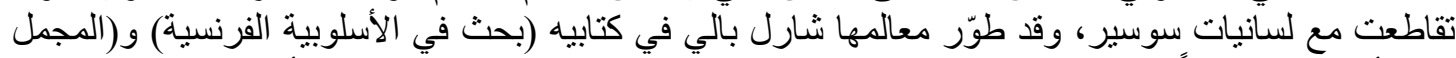

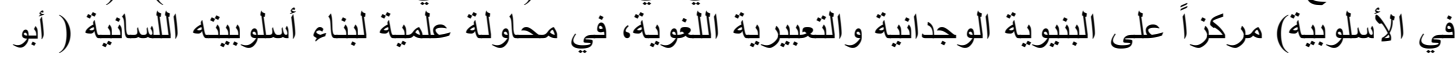

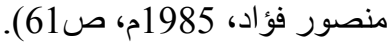

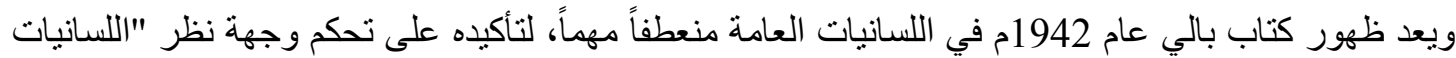

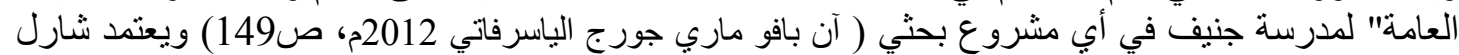

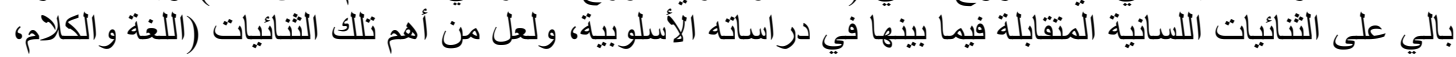

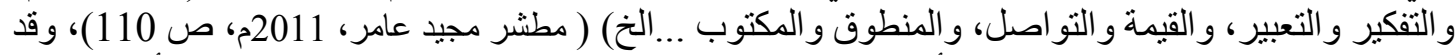

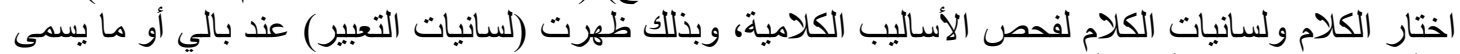

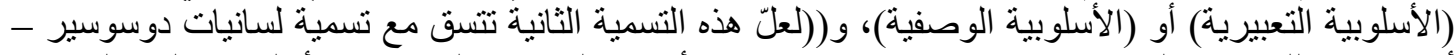

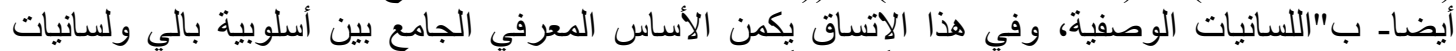

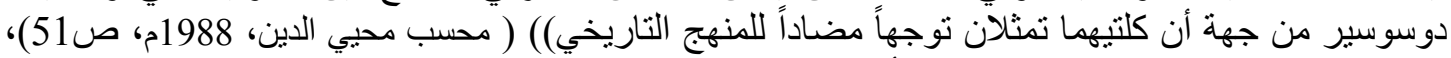

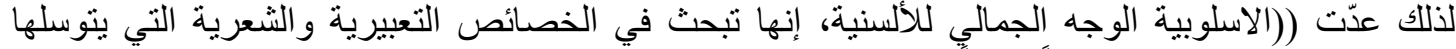

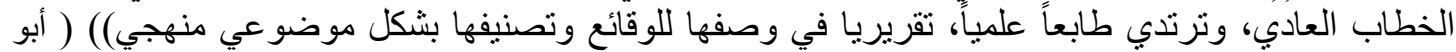

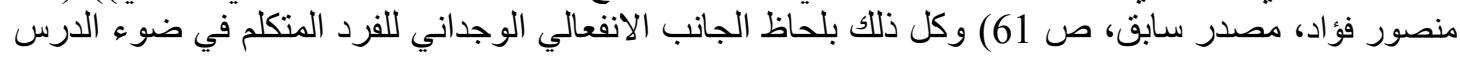
اللساني العلمي لا باعتماد الانطباعيات الحدسية.

وتقوم الأسلوبية التعبيرية عند بالي على دراسة الانجاز اللغوي وارتباطه بالتعبير الانفعالي عند المتكلم بشكل

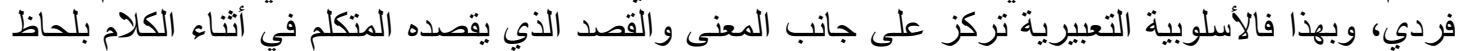
الجانب الانفعالي، و لا تعنى باللفظ و المعنى بوصفهما كيانات مجردة، ومن ثم فالأل الأسلوبية تمعن النظر في العناصر 


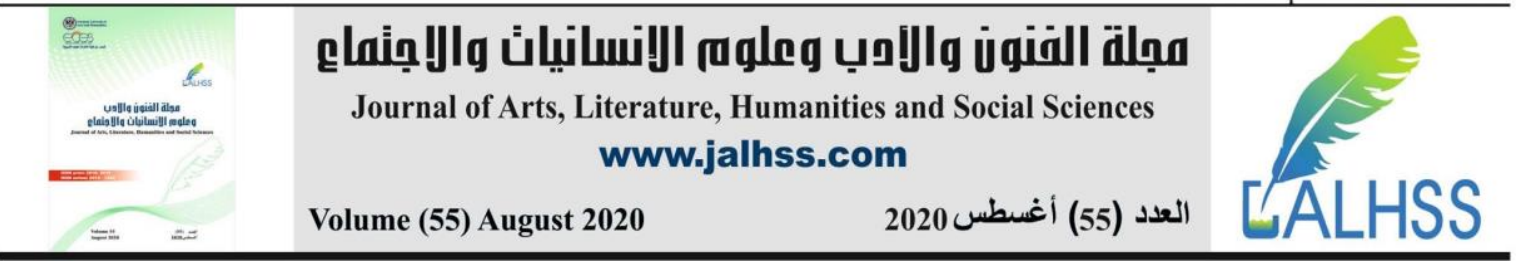

الانفعالية والعاطفية في اللغة؛ بلحاظ أن الاسلوب انجاز فردي يختلف من متكلم إلى آخر ويرتبط بقصدية المتكلم

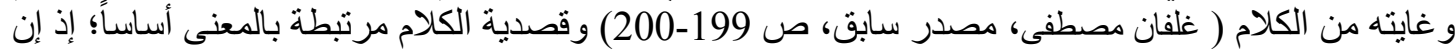
المتكلم يسعى إلى نقل (فكرة/معنى) إلى السامع.

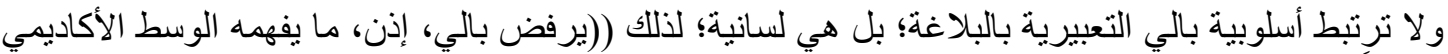

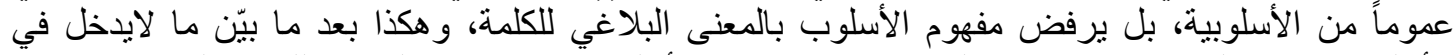

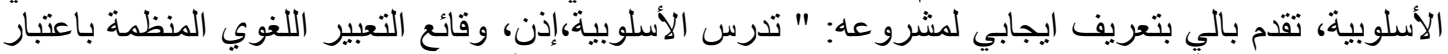

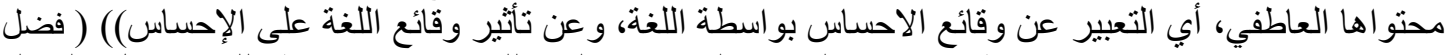

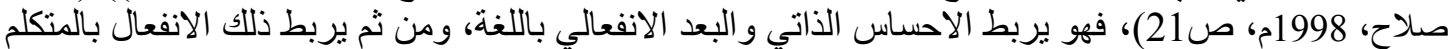

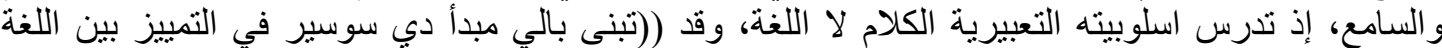
(Langue) وظاهرة الكلام الفردي (Parole)، وطوّره من خلال نظرية التحقيق ...

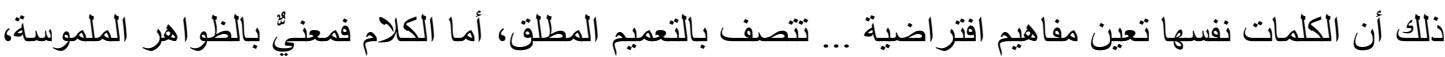

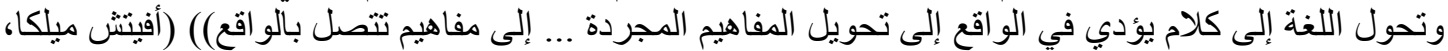

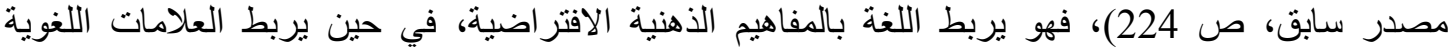

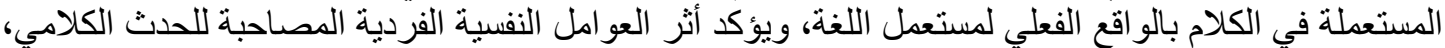

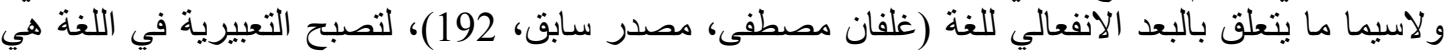

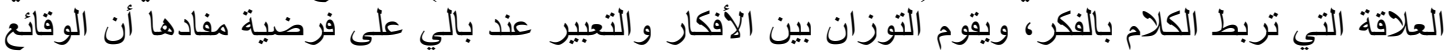

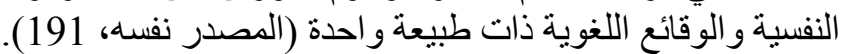

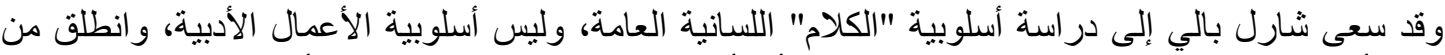

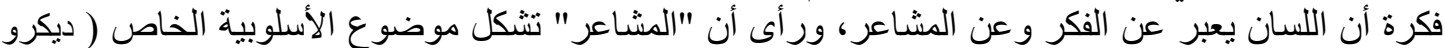

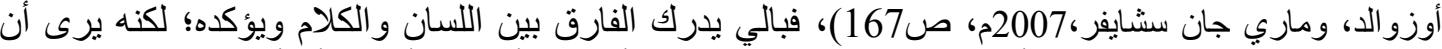

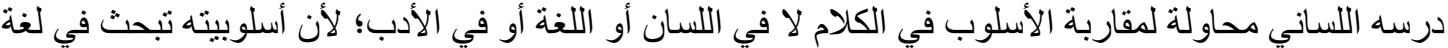

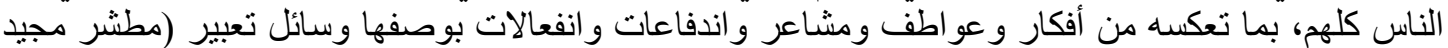

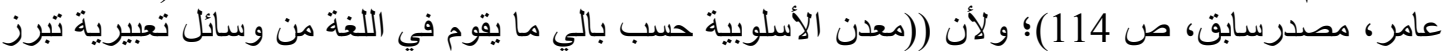

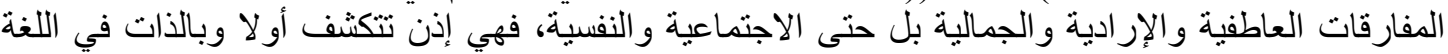

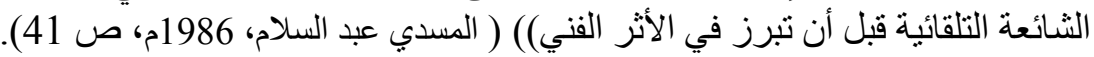

وبذلك فإن بالي اعتمد تقسيم سوسير(لغة/كلام) إلا إنه قام بتأسيس أسلوبية "اللغة المتكلمة" وبذللك أعاد تقييم

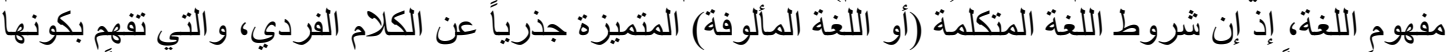

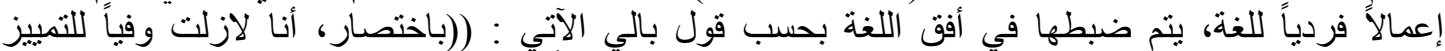

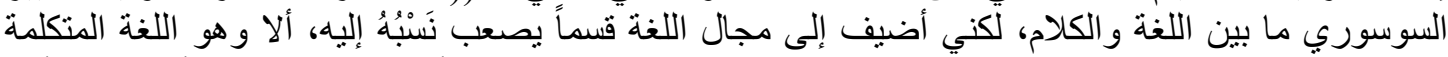

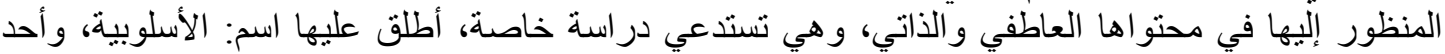

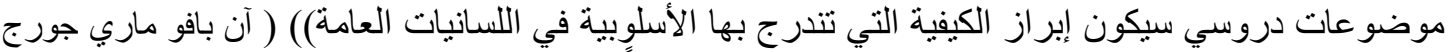

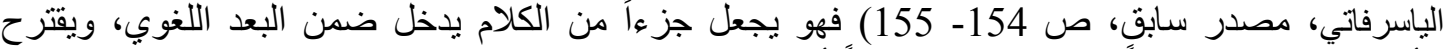

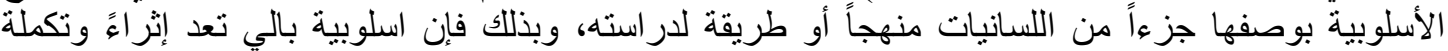

$$
\text { إيجابية للسانيات السوسيرية. (غلفان مصطفى، مصدر سابق، ص صل 212). }
$$

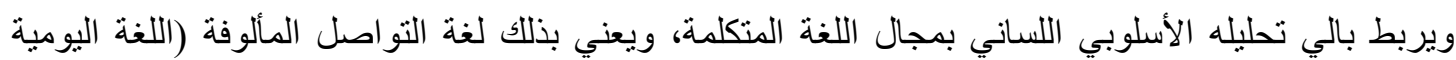

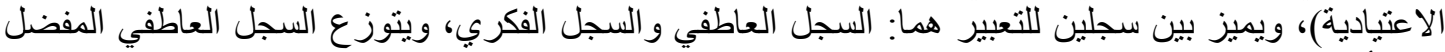

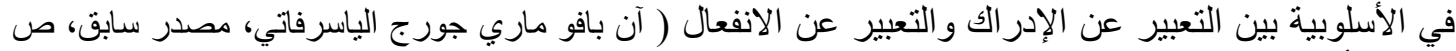

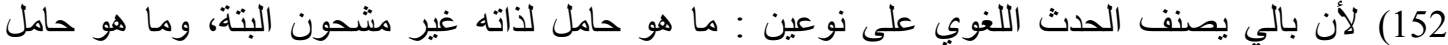

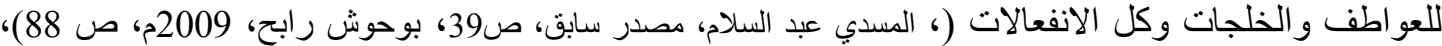
ويتمثل اهتمامه بالحامل للعو اطف و الانفعالات؛ لأنها محور الأسلوبية. 


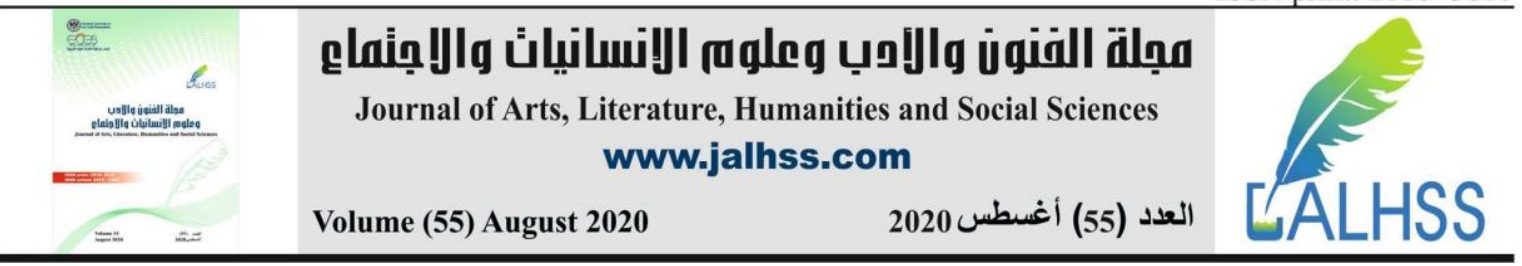

وبما أن بالي بستعمل مصطلح الانفعالية ((يصف كثير من الناس لسانيات بالي بأنها انفعالية ... وينشأ هذا

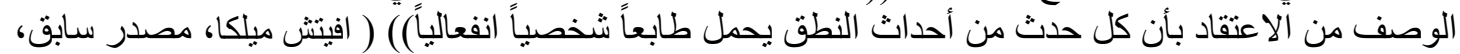

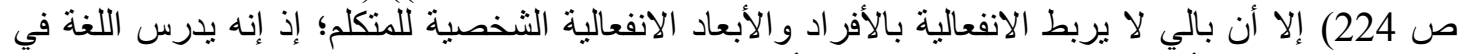

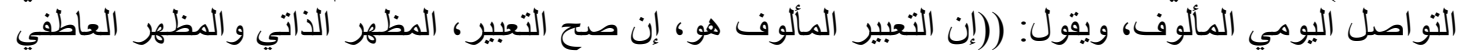

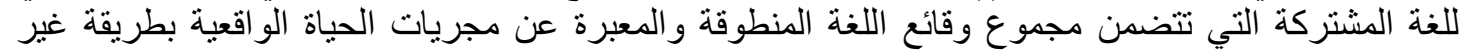
شخصية)) ( آن بافو ماري جورج الياسرفاتي، مصدر سابق، ص التشة 153).

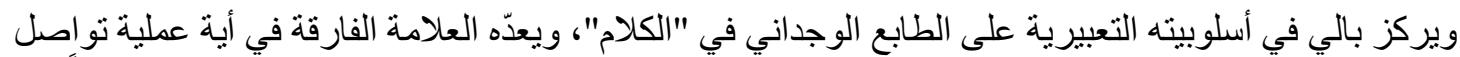

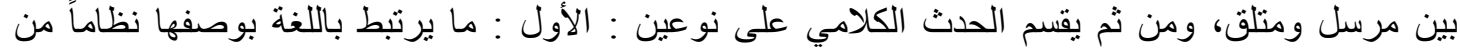

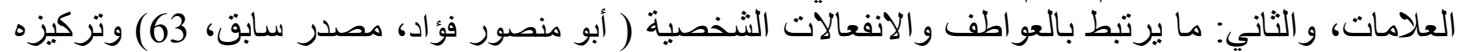

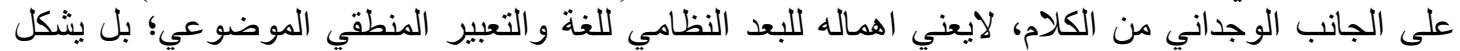

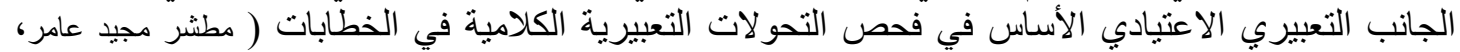

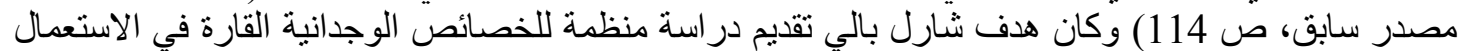

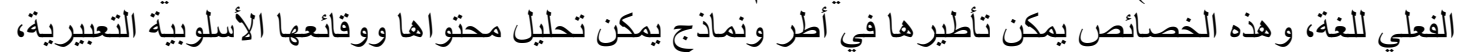

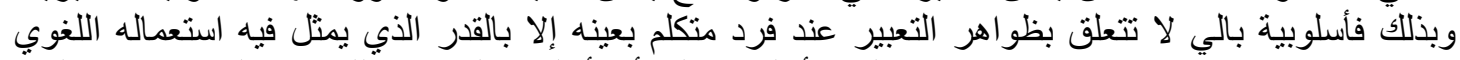

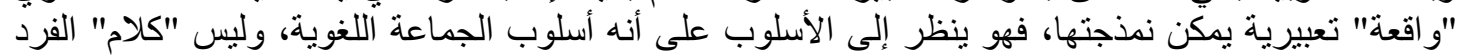

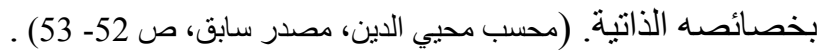

وقد ركز شارل بالي على الطابع العاطفي الانفعالي وارتباطه بفكرتي القيمة والتواصل، فرأى أن الاحتكاك

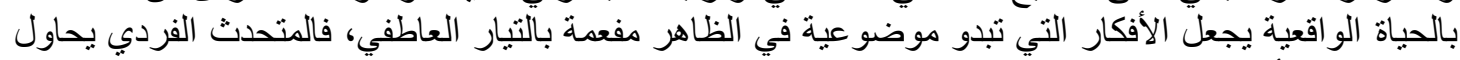

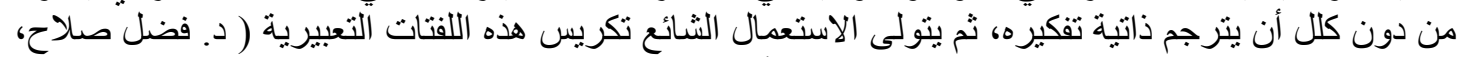

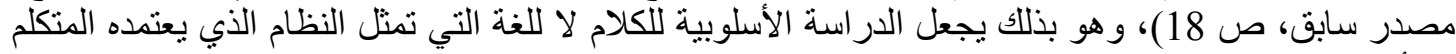

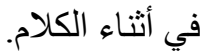

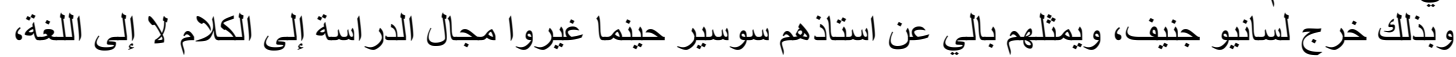

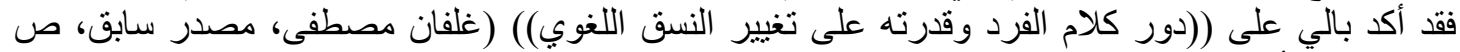

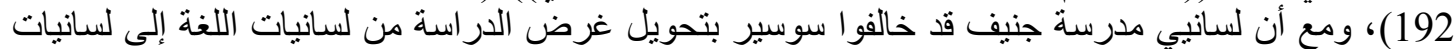

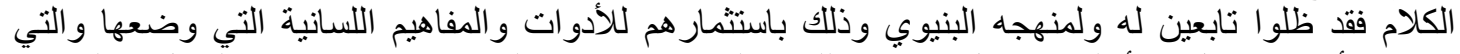

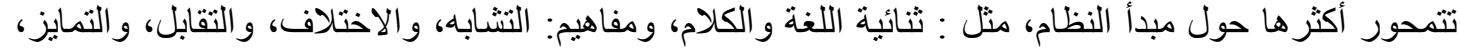

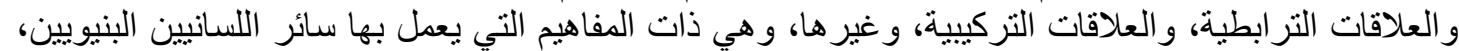

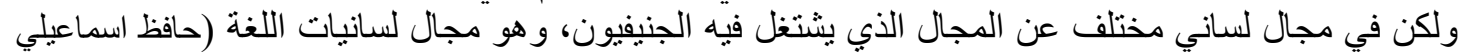

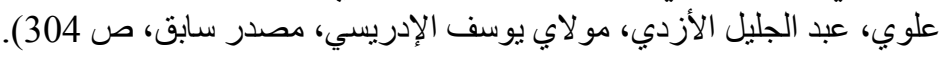

وبحسب تعبير بالي فـ((إن ما تدرسه لسانيات التعبير هو ... الطرق والدو ال التي بواسطتها تتنج اللغة الانفعال))

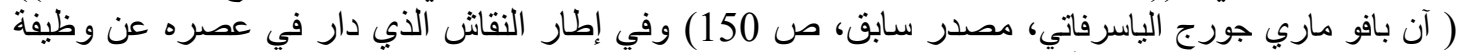

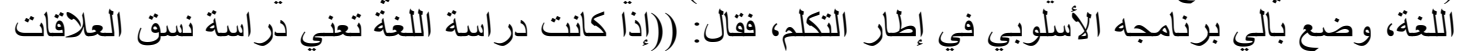

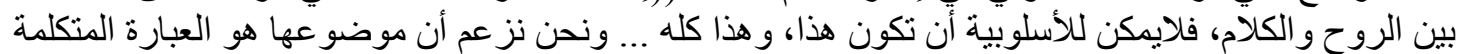

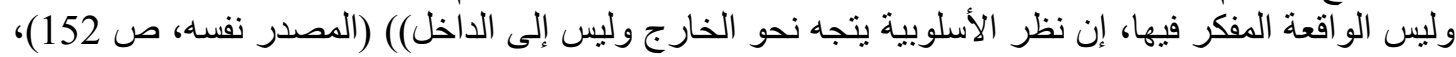

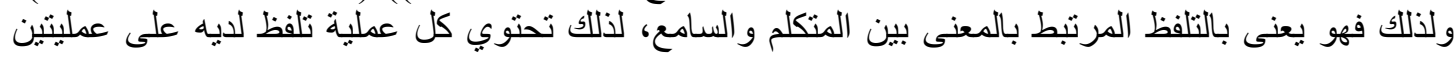
متميزتين هما(غلفان مصطفى، مصدر سابق، صط بالسن 202): 1- تبليغ فكر معين.

2- الصبغة اللغوية تحمل معنى أو فكر اوبعداً انفعاليا.

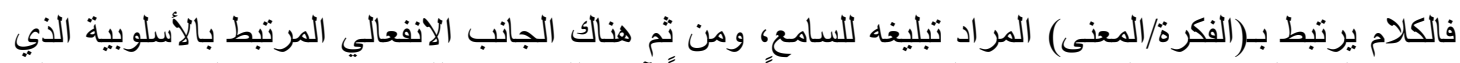

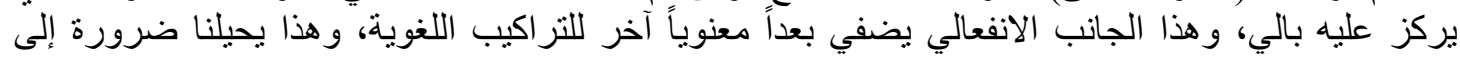
تفريق بالي بين جانبين من المعنى هما (محسب محيب الدين، مصدر سابق، صل صلئ 53): 


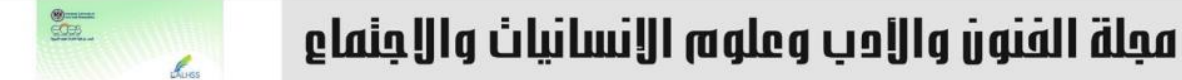 \\ Journal of Arts, Literature, Humanities and Social Sciences \\ www.jalhss.com

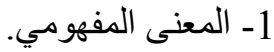

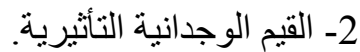

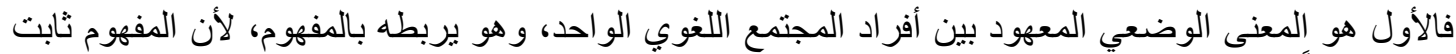

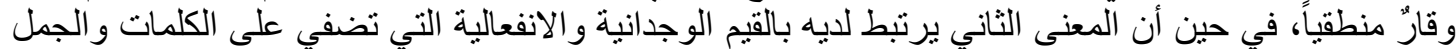
و التر اكيب و النصوص في معند انٍ إضافية أخرى.

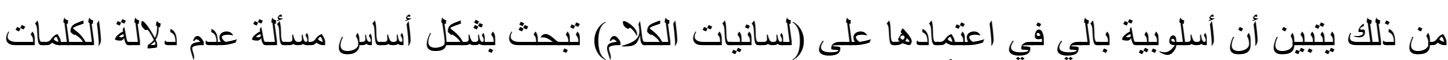

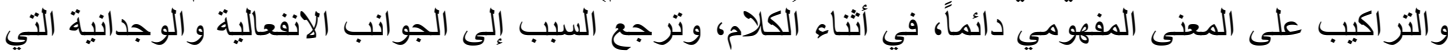
تضفي ظلال معنى أو معانٍ إضافية بلحاظ الموقف الكلامي و البعد الانفعالي للمتكلم و السامع.

ثنانياً: المعنى في لسانيات سيشهاي:

سعى سيشهاي إلى تأسيس علم لسانيات جديد، ينتقل باللسانيات من علم بالوقائع البيولوجية و الوقائع الاجتماعية

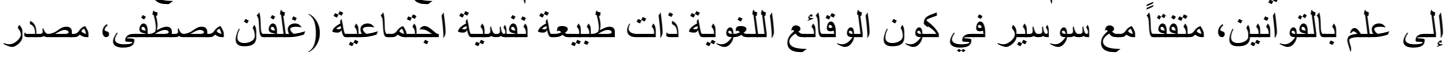

سابق، 207)

ذاع صيت سيشهاي بدر استه في اللسانيات العامة، ويتمثل همه الأساسي في دراسة العلاقة بين العوامل اللسانية

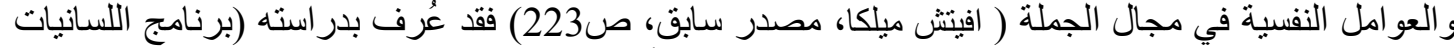
النظرية ومنهجياتها)، و الذي توخى فيه بناء نحو للفكر على أسس نفسية (غلفان مصطفى، مصدر سابق، ص

لذلك ذهب سيشهاي إلى أن مفهوم اللسان ليس معطى ناماً وجاهزاً عند الفرد، ولكنه يبنى تدريجيا ومرحليا

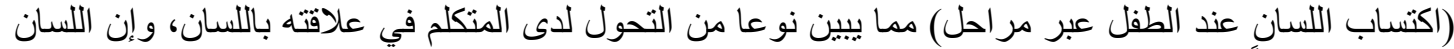

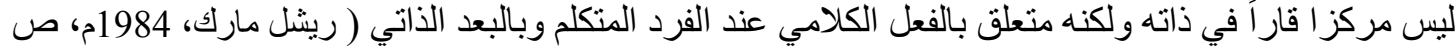

.) 137 132

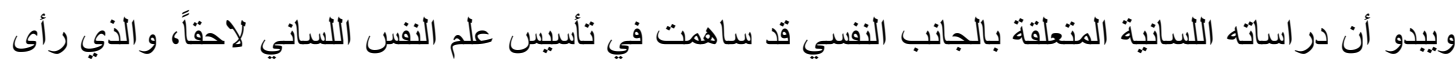

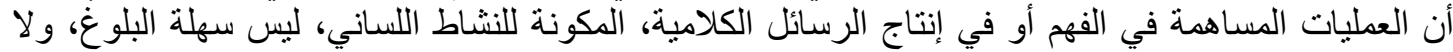

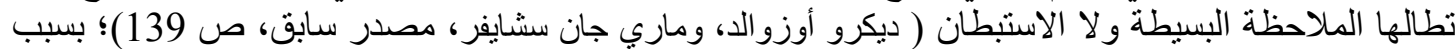

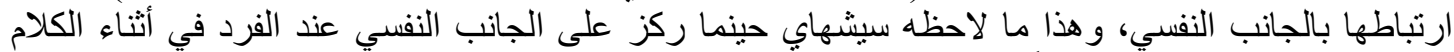

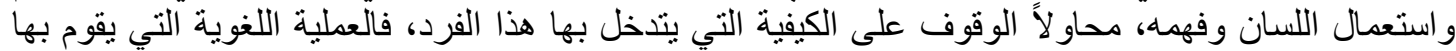

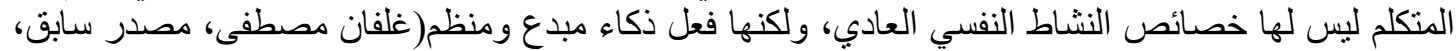

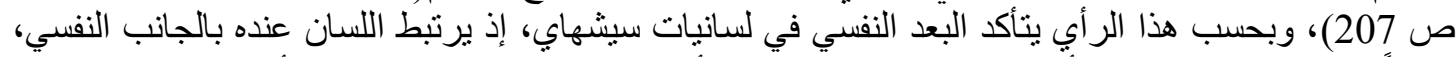

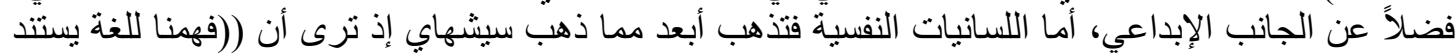

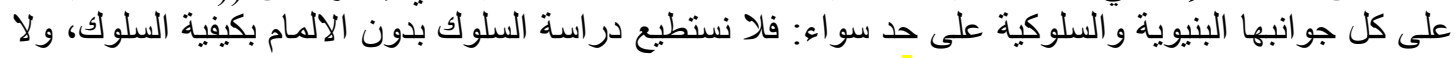

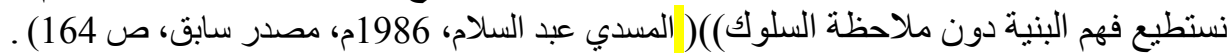

ويدخل المعنى في لسانيات سيشهاي، حينما يرى أن اللسان - بحسب التصور السوسيري- ينفلت من إر ادة الفرد

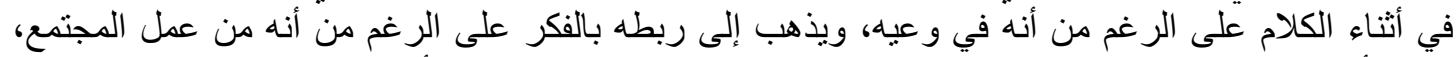

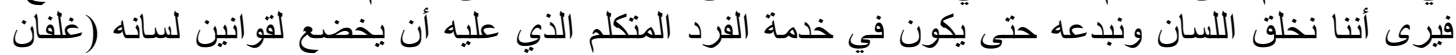

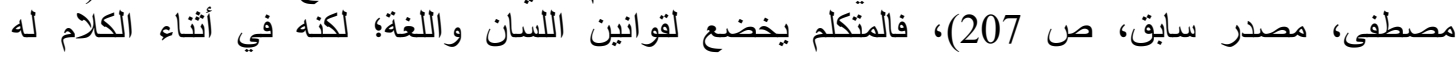
مساحة من الابداع والحرية في أثناء الاستعمال؛ بغية تضمين الكلمات بمعانٍ إضافية تفهم بالنظر لظروف الاستعمال، و لاسيما النفسية منها. 


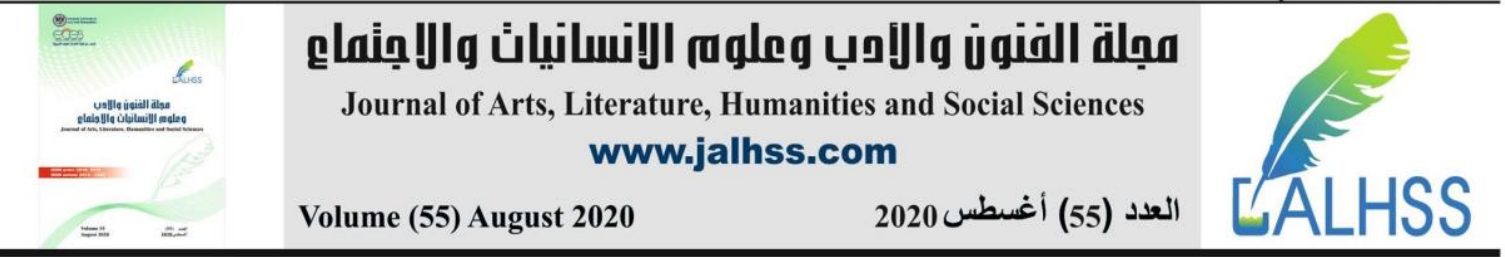

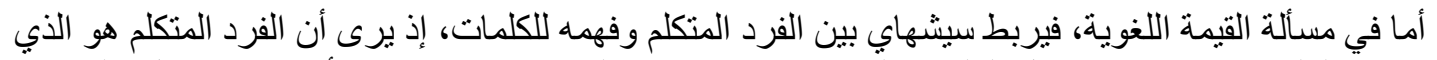

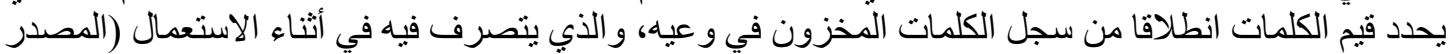

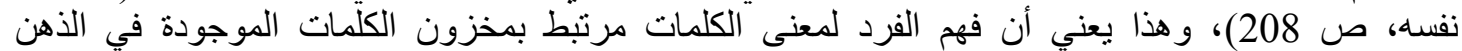

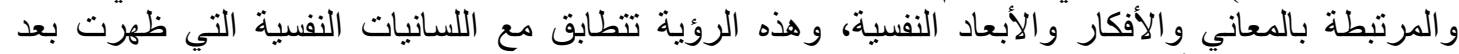

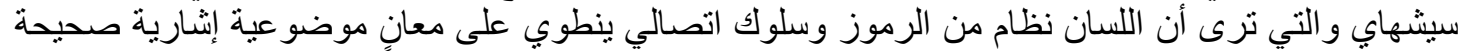

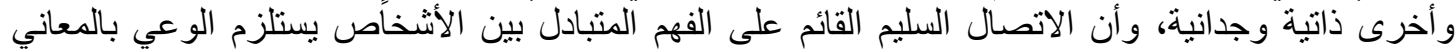

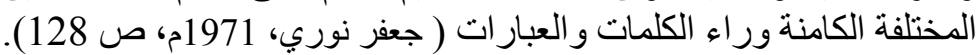

ويربط سيشهاي المعنى بالتأويل، إذ برى أن ((التعبير عن الفكر ليس عملية اعتيادية بسيطة ولكنه استعمال

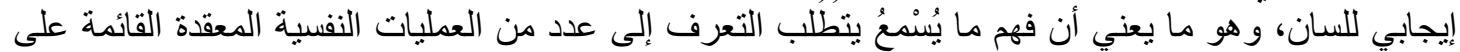

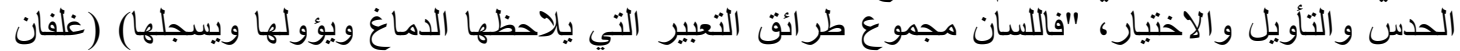

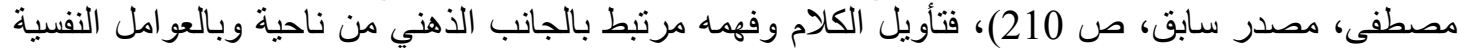

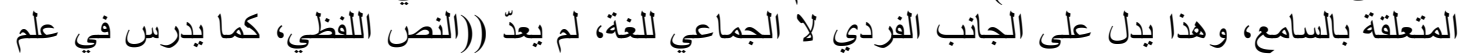

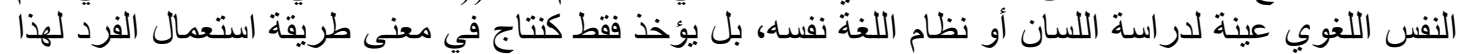

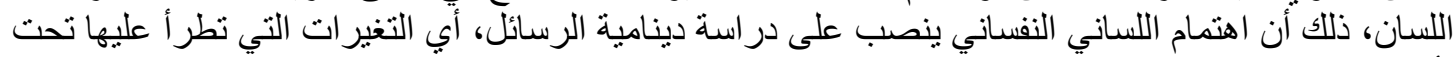

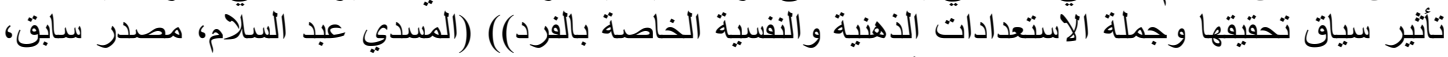
ص 36)، و هذا الجانب يرتبط بالمعنى وتأو يله عند سيثهاي وفي نظر النية اللسانيات النفسية التي سارت على النى خطاه.

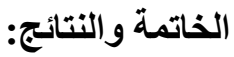

بعد قر اءة متأنية للمقاربة الدلالية عند شيشهاي وبالي توصل البحث إلى النتائج الآتية:

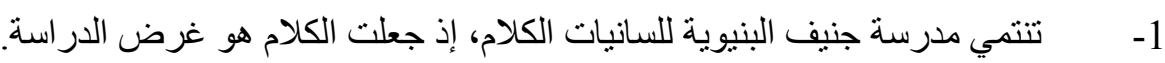
2-2 -

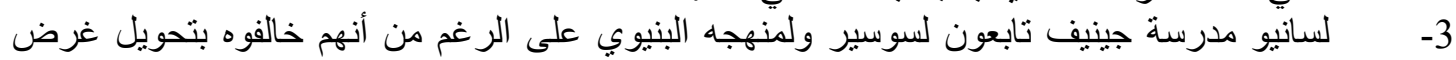
الدر اسة من لسانيات اللغة إلى لسانيات الكلام.

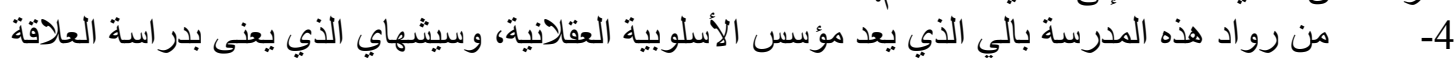

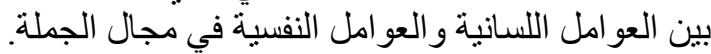

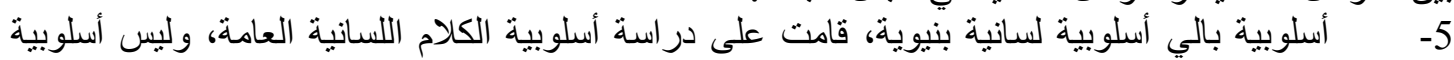

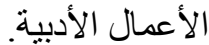
6- يميز بالي بين السجل العاطفي والسجل الفكري، ويرى أن التعبيرية هي العلاقة بين الكلام والفكر،

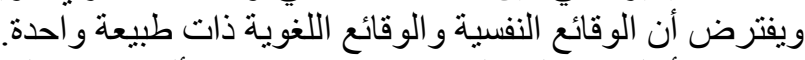

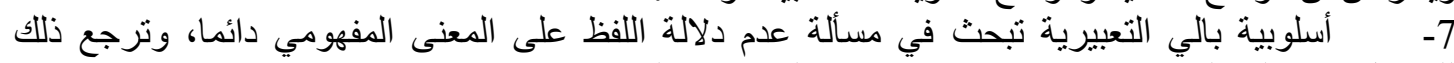

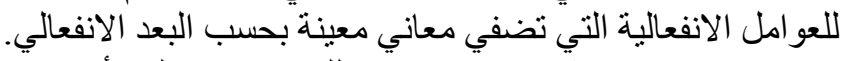

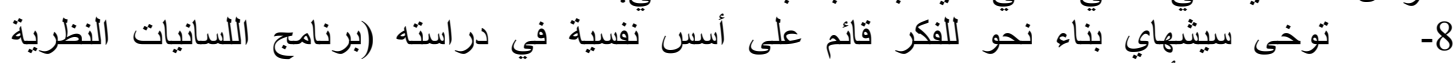

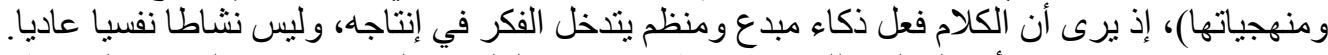

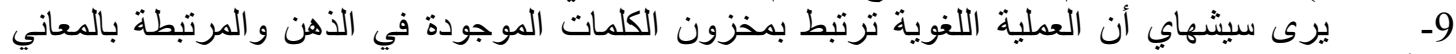
و الأفكار لاى مستعملي اللغة. 


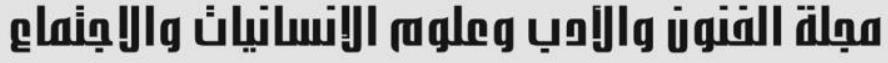

Journal of Arts, Literature, Humanities and Social Sciences www.jalhss.com

المصادر والمراجع

1. أبو منصور فؤاد، 985ه، النقد البنبوي الحسبث بين لبنان وأوربا نصوص، جمالبات، تطلعات، ط1،

بيروت، دار الجيل.

2. افيتش ميلكا ، 2000م، اتجاهات البحث اللساني، ترجمة : سعد عبد العزيز مصلوح وفاء كامل فايد ،

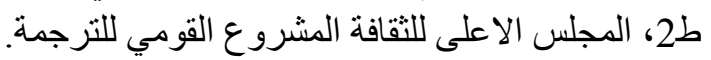

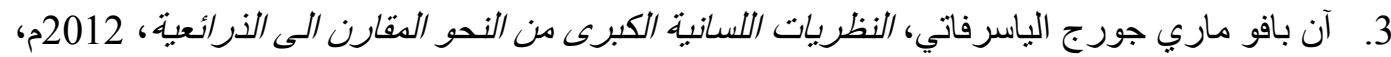

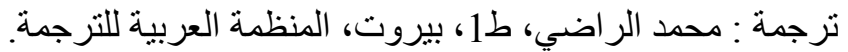

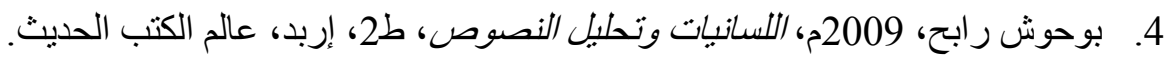

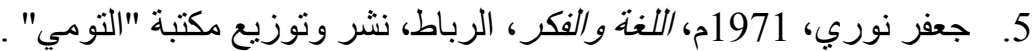

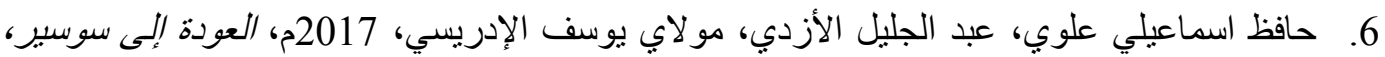

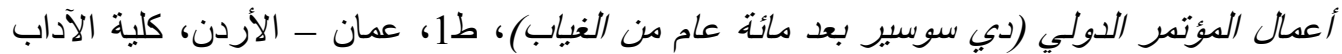

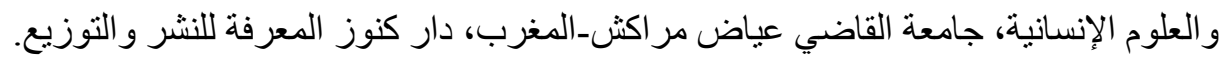

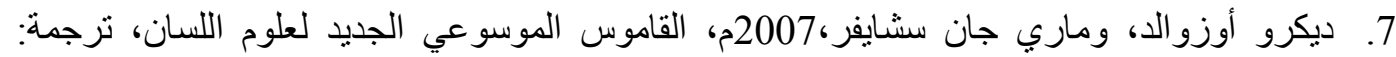

د.منذر عياشي، ط2، بيروت، الماري، المركز الثقافي العربي.

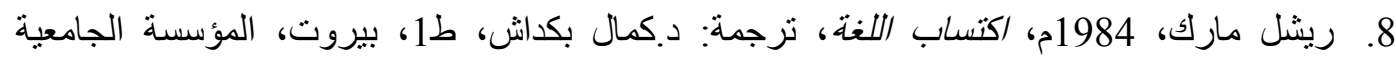
للار اسات و النشر و التوزيع.

9. شنوقة السعيد، 2008م، ددخل إلى الددارس اللسانبة، ط1، القاهرة، المكتبة الأزهرية للتراث.

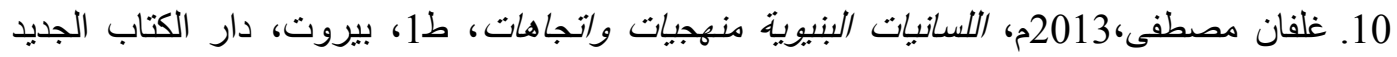

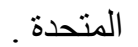

11. فضل صلاح، 1998م، علم الأسلوب مبادئه و إجر اءاته، ط1، القاهرة، دار الثروق.

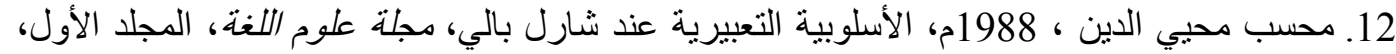

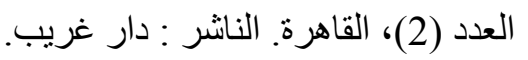

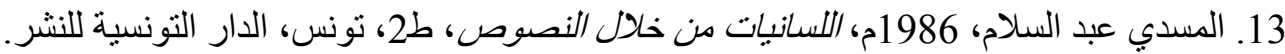

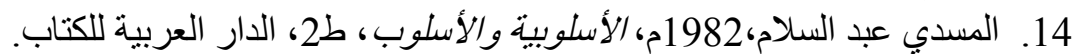

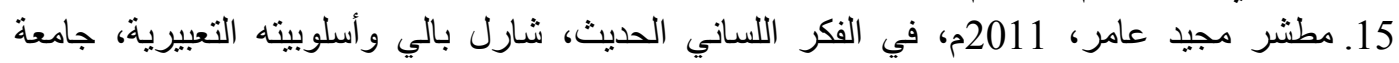

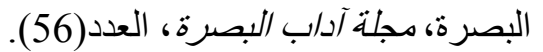

16. هلبش جرهارد، 2003م، تاريخ علم اللغة الحديث، ترجمة: د. سعيد حسن بحيري، القاهرة، مكتبة

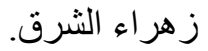

17. هيثن كلاوس، 2010م، القضايا الأساسية في علم اللغة، ترجمة: الدكتور سعيد حسن بحيري، ط2،

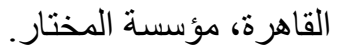




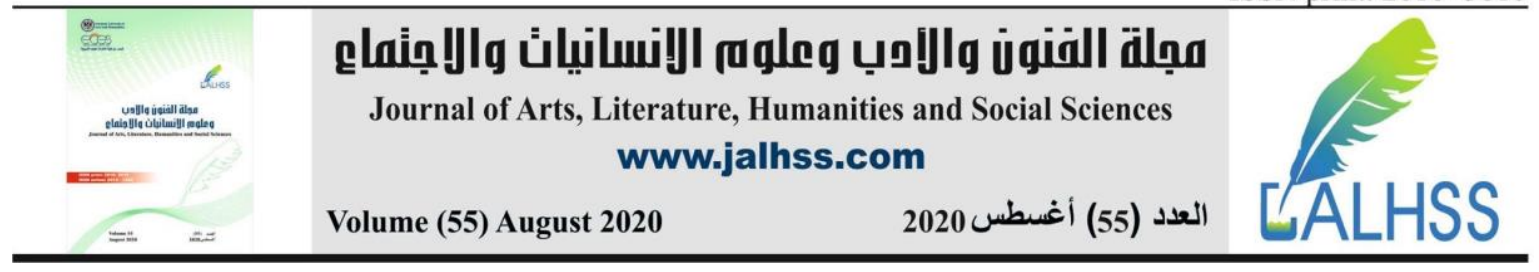

\section{References}

1. Abu Mansour Fouad, 985 AD, modern structural criticism between Lebanon and Europe, texts, aesthetics, aspirations, 1st edition, Beirut, Dar Al-Jeel.

2. Avic Milka, 2000 CE, Trends in Linguistic Research, Translated by: Saad Abdul Aziz Maslouh, Wafa Kamel Fayed, 2nd Edition, The Supreme Council of Culture, The National Project for Translation.

3. Anne Paveau Marie-Georges Al-Yasrafati, "Greater Linguistic Theories from Comparative Syntax to Arterialism, 2012," translated by: Mohamed Radi, 1st edition, Beirut, Arab Organization for Translation.

4. Bouhouch Rabeh, 2009 AD, Linguistics and Textual Analysis, 2nd edition, Irbid, Modern Book World.

5. Ja`far Nouri, 1971 AD, Language and Thought, Rabat, published and distributed by the Tumi Library.

6. Hafez Ismaili Alawi, Abdel Jalil Al-Azdi, Moulay Youssef Al-Idrisi, 2017 AD, Return to Saussure, The work of the International Conference (De Saussure after a hundred years of absence), 1st edition, Amman - Jordan, College of Arts and Humanities, Cadi Ayyad University Marrakech - Morocco , Treasures Knowledge House for Publishing and Distribution.

7. Decro Oswald and Mary Jan Schaeffer, 2007 AD, the new encyclopedic dictionary of tongue science, translation: Dr. Munther Ayachi, 2nd edition, Beirut, Arab Cultural Center.

8. Rachel Mark, 1984 AD, Language Acquisition, translation: Dr. Kamal Bakdash, 1st Edition, Beirut, University Institute for Studies, Publishing and Distribution.

9. Shenouqa Al-Saeed, $2008 \mathrm{AD}$, entrance to the linguistic schools, 1st edition, Cairo, Al-Azhar Heritage Library.

10. Galfan Mustafa, 2013 AD, Structural Linguistics Methodologies and Trends, 1st Edition, Beirut, United New Book House.

11. Fadl Salah, 1998, Methodology, its principles and procedures, 1st edition, Cairo, Dar Al-Shorouk.

12. Mohasib Mohy El-Din, 1988 AD, The Expressive Method at Charles Bali, Journal of Language Sciences, Volume 1, No. 2, Cairo. Publisher: Dar Gharib.

13. Al-Masdi Abdel Salam, 1986 AD, Linguistics Through Texts, 2nd edition, Tunis, Tunisian Publishing House.

14. Al-Masdi Abdul-Salam, 1982 AD, style and style, 2nd edition, the Arab Book House.

15. Mutasher Majid Amer, 2011 AD, in modern linguistic thought, Charles Bali and his expressive style, University of Basra, Journal of Literature, Basra, No. (56).

16. Helbash Gerhard, 2003 CE, History of Modern Linguistics, translation: Dr. Saeed Hassan Beheiri, Cairo, Zahraa Al-Sharq Library.

17. Hichen Klaus, 2010 AD, the main issues in linguistics, translation: Dr. Saeed Hassan Beheiri, 2nd edition, Cairo, Al-Mukhtar Foundation 